\title{
Design and \\ Intelligent Machines
}

\author{
William Regli
}

Many are interested in the design of intelligent machines. I am interested in design and how intelligent machines can transform this human endeavor in positive ways. I would like us to renew our consideration of some of the fundamental questions from the field of artificial intelligence, questions about human creativity and agency, in the context of design.

$\mathrm{V}$ arious leading figures have recently been warning that the future of humanity is threatened by the rise of artificial intelligence or by superintelligent - even self-aware - machines of our own design. These forebodings envision machines that, in the pursuit of their own goals, ultimately dominate or extinguish their creators. But while much ink has been spilled on the prospect of manufacturing monsters beyond our control, surprisingly little attention has been focused on the actual challenge of designing machines that seamlessly integrate even a few of our leading technologies into a smoothly operating everyday device, much less create a self-aware, internally motivated, hegemonistic intelligence. 
The fact is, despite enormous individual engineering advances in recent years, we remain woefully inadequate when it comes to the art of design - the enigmatic and still largely unautomated process of synthesizing multiple elements into final products. If anything, we should be not afraid of what we are designing but rather accelerating our efforts in the domain of design - in part to design machines that can, in turn, help us become better designers.

Herbert Simon, who in 1978 was awarded the Nobel Prize in economics for his work on bounded rationality and organizational behavior, argued that design is the activity that most fundamentally makes us human. In his seminal work, The Sciences of the Artificial, Simon states that every person is, at heart, a designer, and that the art of design elevates us all.

Everyone designs who devises courses of action aimed at changing existing situations into preferred ones. The intellectual activity that produces material artifacts is no different fundamentally from the one that prescribes remedies for a sick patient or the one that devises a new sales plan for a company or a social welfare policy for a state. Design, so construed, is the core of all professional training; it is the principal mark that distinguishes the professions from the sciences. Schools of engineering, as well as schools of architecture, business, education, law, and medicine, are all centrally concerned with the process of design. (Simon 1996)

The modern world is the product of design. From the social systems we have for governments and corporations, to our physical infrastructure, to the artifacts of everyday life, design is all around us. Yet our processes of design today are largely unchanged from those of a millennium ago, when the Republic of Venice established the Arsenale, a factory of unprecedented scale and organization that foreshadowed the innovations of the industrial revolution. Early concepts for interchangeable parts, the assembly line, and the organizational division of labor and process optimization all were part of the design and manufacturing process in this ancient Venetian shipyard.

Today's innovations in robotics, advanced materials and additive manufacturing require newer and more creative design processes, enabling an entirely new kind of Arsenale - an Arsenale in which computers work as our creative partners. Such a partnership would augment human design capabilities and enable us to envision radically different solutions to our problems. For example, traditional design divides functionality in a hierarchical manner. Nature does not work this way: Just as the bird's wing is designed to generate lift but also harvest energy and create thrust, today's design opportunities are those that integrate mechanical, electrical, optical, and thermodynamic features with multiple behaviors and interactions across different physics domains. The maturation of individual technologies is allowing us to create systems that are of previously unimaginable complexity, but that are extraordinarily difficult to bring fully to fruition because we lack design tools able to operate on such complex planes.

In 1960 J. C. R. Licklider authored a seminar paper called Man-Computer Symbiosis, the basic tenet of which is that machines can be designed to work in partnership with people to extend and augment human cognitive capabilities (Licklider 1960). We have created impressive systems that can enhance our chess playing, help us understand foreign languages, and learn to recognize objects in images and videos, but we have not yet enlisted machine intelligence to enhance what is the quintessential human activity: design.

Of course, we have computer-aided design tools. But most of these are essentially extensions of engineering and manufacturing practices going back more than two centuries. They enable the dimensional specifications needed to take advantage of the innovation of interchangeable parts, which has roots in the Arsenale and blossomed in the U.S. armories at Harpers Ferry, Virginia, and Springfield, Massachusetts. Established standards for dimensioning, measuring, and inspecting parts are all encoded in drafting protocols and geometric dimensioning and tolerancing practices that form the basis of our modern engineering design tools - allowing users to transcribe the designs they've already conceptualized. And while digital representation can then foster models that can drive simulation, analysis, and other applications, these tools are not really design synthesis tools or creativity augmenters. They simply verify various aspects of what is in the original drawing or model.

Modern computer-augmented - as opposed to merely aided - design environments would (and should) look very different. The computer would be a partner with the designer, or with a team of designers, to help devise a course of action aimed at creating an artifact or system that, when put to work in the world, would produce a desired effect. If we had design processes to match the technologies we have today, they would not simply mimic physical tools and processes but would extend the creative capacity of designers. It would be the difference between simply assessing the situation on a chessboard and actually, actively playing competitive chess-not just helping designers turn their ideas into reality but helping them explore configurations they could not or would not have conceived of alone.

Consider that today, our best mechanical engineering students are packed with facts about thermodynamics and combustion; our best electrical engineers learn about control theory and the harnessing of the electromagnetic spectrum; our computer scientists understand the syntax and semantics of programming and the principles for the design of algorithms and data structures. With computer-augmented design tools able to nimbly synthesize all these domains of expertise, many more prospective designers would have access to a grand 
master who could work with them to generate unusual and nonintuitive strategies that would take full advantage of the spectrum of state-of-the-art technologies.

Ultimately, more sophisticated design tools will be only half the solution. The other half will involve the designers themselves, who will need to be trained in entirely new ways of thinking - ways that do not fit neatly into academic departments and will require new models of transdisciplinary education. New curricula will need to explore such questions as "How do we ensure that products designed so creatively and in many cases without physical prototypes can be trusted?" and "Given the new creative potential, how do we keep ourselves from designing something we will regret?"

At this moment, where are the opportunities for transformation? I think there are three. First, the central role of computing and information requires we rethink how we instruct designers and, more broadly, how we conduct engineering education in general. Physics, as applied to different questions, has been the principal language for engineering and design since the age of Napoleon. The rise of computation challenges long-held beliefs about what should be taught to aspiring designers and engineers. Algorithmic thinking offers an alternative worldview to systems of differential equations, but one that is not given central treatment in mainstream science and engineering curricula.

The second opportunity is data. While unprecedented volumes of data have transformed areas of physics, medicine, biology, and business into information disciplines yet, within the practice of engineering, data often remains a second class citizen. We can envision a future in which designers have access to vast treasure-troves of prior knowledge and experience; analysis tools will leverage experimental results; and design systems will harvest this data to augment our cognitive memory. In this vision, data is the central product of design - not a by-product. To get there, we must transform disciplines such as engineering into an information discipline.

Last, and most significantly, this new space of possible design options is vast and the only way we will be able to navigate it is if we have computers that work in partnership with and learn from us: how to anticipate our mistakes, open our blind spots, and stimulate our thinking. Such intelligent software will be our partners in creation, creating a kind of codependency that I believe will be not only healthy but essential for our species' future.

If design is what makes us human and is a human imperative, then humans stand on the brink today of remaking not just our world but ourselves. But we cannot and should not embark on this process alone. We should enlist our best intelligences - carbonbased and silicon-based - and work hand in hand with creative machines to design and build an ele-

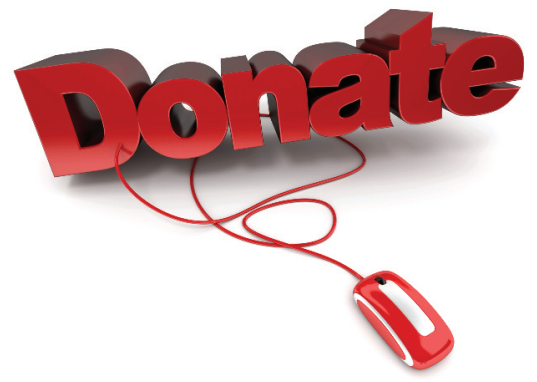

\section{AAAI Gifts Program}

AAAI invites all members and other interested parties to consider a gift to help support the dozens of programs that AAAI currently sponsors. For more information about the Gift Program, please see write to us at donate17@ aaai.org.

\section{Support AAAI Open Access}

AAAI counts on you to help us deliver the latest information about artificial intelligence to the scientific community. To enable us to continue this effort, we invite you to consider an additional gift to AAAI. For information on how you can contribute to the open access initiative, please see www.aaai.org and click on "Gifts."

AAAI is a 501c3 charitable organization. Your contribution may be tax deductible.

gantly sustainable world for ourselves and for generations to come.

\section{Distribution Statement}

Approved for public release. Distribution is unlimited.

\section{References}

Licklider, J. C. R. 1960. Man-Computer Symbiosis. IRE Transactions of Human Factors in Electronics HFE-1(1): 4-11. doi.org/10.1109/THFE2.1960.4503259

Simon, H. 1996. The Sciences of the Artificial. Cambridge, MA: The MIT Press.

William Regli is the acting director of the Defense Sciences Office for DARPA, on leave from his position as a professor of computer and information science for Drexel University's College of Computing and Informatics. He's a fellow of the IEEE Computer Society and a senior member of both ACM and the Association for the Advancement of Artificial Intelligence (AAAI). Contact him at william.regli@darpa.mil. 